\title{
Tattoos and Transfusion-Transmitted Disease Risk: Implications for the Screening of Blood Donors in Brazil
}

\author{
Sérgio de A. Nishioka, Theresa W. Gyorkos \\ and J. D. MacLean
}

\author{
Department of Epidemiology and Biostatistics, McGill \\ University, Montreal, Canada; Division of Clinical \\ Epidemiology, Montreal General Hospital, Montreal, \\ Canada; School of Medicine, FederalUniversity of \\ Uberlândia, Uberlândia, Brazil; McGill University \\ Centre for Tropical Diseases, Montreal General \\ Hospital, Montreal, Canada
}

\begin{abstract}
Having a tattoo has been associated with serological evidence of hepatitis $B$ and $C$ viruses, as well as human immunodeficiency virus infections and syphilis; all of these are known to be transmissible by blood transfusion. These associations are of higher magnitude for individuals with nonprofessionally-applied tattoos and with two or more tattoos. Tattoos are common among drug addicts and prisoners, conditions that are also associated with transfusion-transmitted diseases. We examined the implications of these associations for the screening of blood donors in Brazil. Numbers of individuals who would be correctly or unnecessarily deferred from blood donation on the basis of the presence of tattoos, and on their number and type, were calculated for different prevalence situations based on published odds ratios. If having a tattoo was made a deferral criterion, cost savings (due to a reduced need for laboratory testing and subsequent follow-up) would accrue at the expense of the deferral of appropriate donors. Restricting deferral to more 'at-risk' sub-groups of tattooed individuals would correctly defer less individuals and would also reduce the numbers of potential donors unnecessarily deferred. Key factors in balancing cost savings and unnecessary deferrals include the magnitude of the pool of blood donors in the population, the prevalence of individuals with tattoos and the 'culture' of tattoos in the population. Tattoos can therefore be an efficient criterion for the screening of blood donors in certain settings, a finding that requires corroboration from larger population-based studies.
\end{abstract}

Key Words: Brazil, blood donors, screening, tattoos, transfusion-transmitted diseases.

The treatment of severe trauma and of several lifethreatening medical conditions still relies very much on

Received on 15 January 2001; revised 7 June 2002.

Address for correspondence: Dr. Theresa W. Gyorkos, Division of Clinical Epidemiology, Montreal General Hospital, 1650 Cedar Av., Room L10 420, Montreal (Quebec), H3G 1A4, Canada. Telephone: +1(514)937-6011 extension 4721. Fax: +1(514)934-8293. E-mail:mdgt@musica.mcgill.ca

Footnote: Dr. Nishioka was partially supported by a scholarship (process number 200440/94-2) from the Conselho Nacional de Desenvolvimento Científico e Tecnológico (CNPq). Dr. Gyorkos holds a senior career award from the Fonds de la Recherche en Santé du Québec.

The Brazilian Journal of Infectious Diseases 2002;6(4):172-180 (C) 2002 by The Brazilian Journal of Infectious Diseases and Contexto Publishing. All rights reserved.

$1413-8670$ the transfusion of blood and blood products. The demand for platelet and clotting factors is also continually increasing. Although there has been some misuse related to the inappropriate transfusion of packed red cells, and there is now evidence that transfusion should be performed only at lower concentrations of hemoglobin than usually indicated in the past for elective surgery [1] and for the treatment of critically ill patients [2], in practice alternatives to transfusion are very limited. Blood-saving measures have been developed in an attempt to decrease the need for allogenic transfusion. Pre-operative autologous donation, in which the patient donates blood in advance for his/her own use in an elective surgical procedure, is one such measure [3]. Intraoperative cell salvage, which involves the collection and re-transfusion of shed red 
blood cells during surgery, is a promising technique, but still complex and expensive. The present evidence indicates that acute normovolemic hemodilution does not reduce the amount of allogenic transfusion needed, and artificial oxygen-carrying solutions are still being investigated [4]. Finally, erythropoietin therapy has been shown to be effective in avoiding the need for blood transfusions in patients with chronic renal failure and cancer, but its cost has limited its widespread use [5]. The source of blood donors that is generally acceptable consists of unpaid volunteer donors. Although paid "professional" donors still exist in both developed and developing areas around the world, the use of these individuals is discouraged given that they have a higher likelihood for testing positive for transfusion-transmitted diseases (TTDs) and for being anemic due to poor nutrition and repeated donations [3]. The donation process is preceded by a pre-donation donor evaluation, which consists of an interview that aims to detect risk factors for TTDs and for blood donation itself. This is followed by the determination of the level of hemoglobin in capillary blood collected from a finger prick, for the detection of anemia. In the interview there are, among others, questions regarding the donors' sexual preference, history of previous sexually transmitted diseases, intravenous (IV) drug use history, and exposure to or medical history of diseases such as hepatitis, malaria and Chagas' disease [6]. Usually the presence of a single risk factor is enough for the deferral of the blood donor, which can be temporary or permanent, depending on the reason. Those who pass the first two steps (interview and hemoglobin determination) have about $500 \mathrm{ml}$ of their blood collected into special plastic bags, but this blood is only transfused to someone after tests determine its suitability. The aim is to avoid transmission by transfusion of a number of infections, including hepatitis $B$ virus (HBV), hepatitis $\mathrm{C}$ virus ( $\mathrm{HCV}$ ) and human immunodeficiency virus (HIV) infections, Chagas' disease and syphilis.

With the improvement of serological tests used for donor screening, the current risk of acquiring an infectious disease by transfusion is very low. A cohort study of recipients of over 20,000 units of blood in England did not detect a single case of TTD [7].
However, safety of the donated blood for those who need to receive it has a cost. The cost of laboratory screening of diseases is spiraling upwards, with the addition of tests for new diseases, and with the decision to use more sophisticated (and expensive) tests to narrow down the seronegative window period and to decrease adverse reactions. In Britain the cost of a single unit of packed red cells was expected to increase from $£ 29.14$ to $£ 78.88$ from 1998 to 1999 [4]. In Brazil, in 1997 and 1998, approximately 800,000 individuals who volunteered to donate blood were rejected as donors ( $40 \%$ of the total), and almost 400,000 blood bags were discarded due to a positive blood test, representing a loss of about 25 million US dollars for the Ministry of Health [8].

A way to decrease blood transfusion-related costs is to rely heavily on regular (repeat or life-long) donors. These individuals are probably the best possible donors given that they are less likely to have their blood rejected (because it has already been tested) and to a lesser extent because their incidence of symptoms related to blood-letting is lower. However, a certain percentage of new donors is always required, and an improvement in the donor selection process is a major need [6]. If, in the screening interview, people who are more likely to be deferred by a positive serological test than the general population of donors are identified, costs related to serological tests and the use of expensive plastic bags will be avoided. Therefore it is important that the information collected in the screening interview be used in the best possible way (as, until blood is collected, costs are minimal).

One question that is asked during the screening interview for blood donors is whether the individual has a tattoo, and if so whether it was done in the last 12 months. An individual in this situation is deferred temporarily until 12 months after his/her (last) tattoo, a period of time that covers the window period of negative serological tests for TTDs $[9,10]$. Having a recent tattoo is a major cause of deferral in Singapore [11]. Tattoos have been shown or suggested to be associated with the transmission of $\mathrm{HBV}, \mathrm{HCV}$ and HIV infections and syphilis [12-22]. Several epidemiological studies have shown an association 
between tattooing and HBV [23-30], HCV [31-40] and HIV [41] infections. Other studies, however, have not shown or were unable to demonstrate such an association [30,42-51]. Tattoos have also been associated with drug abuse and incarceration [52,53], which are also risk factors for several TTDs. Based on the rationale that tattoos could be used as a surrogate for these risk factors, for some time in Brazil tattooed blood donor candidates were deferred for 10 years since their last tattoo [54]. The increasing number of tattooed individuals among young adults, who represent the majority of blood donors in that country, was the likely reason why the policy has changed to temporary deferral for 12 months after the last tattoo (Brazilian Ministry of Health, internal document).

We recently carried out a cross-sectional matched study in a Brazilian hospital that aimed to assess the association between tattoos, their characteristics and the circumstances under which they were performed, and TTDs [55-57]. Based on the findings of this study, we discuss here the usefulness of using more detailed information on tattoos for the screening of blood donors inBrazil.

\section{Materials and Methods}

The data, summarized in Table 1, are from a crosssectional matched study carried out from April, 1998, to January, 2000, in a teaching hospital in Uberlândia, Brazil [55-57]. Briefly, the study was aimed at assessing the association between tattoos and positive serological tests for TTDs (HBV, HCV and HIV infections, syphilis and Chagas' disease), and included 345 adults aged 18 years or older who were hospitalized, went to the outpatient clinic, or volunteered to donate blood. Individuals with tattoos $(\mathrm{n}=182)$ who gave informed consent to participate in the study were matched by sex, age and main clinical complaint to individuals without tattoos $(\mathrm{n}=163)$, and all the study subjects were interviewed and gave a sample of blood for the determination of serological markers of $\mathrm{HBV}$ infection (HBV surface antigen [HBsAg] and HBV core antibody [anti-HBc], both determined by enzyme- linked immunoassays [ELISA]), HCV infection(HCV antibodies [anti-HCV] determined by ELISA), HIV infection (HIV antibodies [anti-HIV], determined by ELISA), syphilis (determined by a VDRL test), and Chagas' disease (antibodies to Trypanosoma cruzi determined by indirect immunofluorescence, ELISA or passive hemagglutination). A positive outcome was determined by at least one positive test. Analysis restricted to the group of tattooed subjects assessed whether the odds of testing positive to TTDs was associated with the number and design of tattoos, and by whom (professional vs. nonprofessional tattooist) and under which conditions they were performed (use of disposable or new needles, and exclusive use or use of new dyes).

We used the crude odds ratio point estimate of having a tattoo and testing positive for at least one serological marker of HBV, HCV and HIV infection, syphilis or Chagas' disease to calculate the total number of patients in a hypothetical population that would be deferred if having a tattoo was a deferral criterion. Based on plausible scenarios of different prevalences of TTDs and tattoos in this hypothetical population (figures that were based on previous published [58] and unpublished data and are likely to be found in a Brazilian blood bank in real life) we estimated the proportion of individuals who would be both correctly and unnecessarily deferred during the screening interview because of having a tattoo. We then assessed whether information on number and type of tattoo could contribute to improving the efficiency of the screening process. We also extrapolated some of the results for Brazil using figures that were provided by Drs. Helio Moraes-Souza and Silvano Wendel during a workshop on transfusional Chagas' disease during the Annual Meeting on Applied Research in Chagas' Disease, in Uberaba, Brazil, 1999 (unpublished data).

\section{Results}

In our cross-sectional matched study the crude odds ratio (OR) estimate of having a tattoo and testing positive for at least one serological test for a TTD was 
2.99 (95\% CI: 1.71, 5.26) [55] (Table 1). In that study population having a tattoo was highly associated with IV drug use (OR: 45.84, 95\% CI: 2.76, 762) and previous incarceration (OR: 28.14, 95\% CI: 1.67 , 476). In fact, all subjects in that study who had been incarcerated or admitted IV drug use had tattoos. Table 2 shows the expected numbers of TTD seropositive donors with tattoos in different scenarios of prevalence of tattoos among the donor population ( $2 \%$ and $4 \%$ ) and positive screening serological tests for TTDs among the individuals without tattoos $(5 \%, 10 \%$ and $15 \%)$. These figures were calculated for a hypothetical group of 10,000 new blood donors (number expected in a year for a medium sized blood bank in Brazil), assuming a relative risk of 3 for individuals with tattoos having a positive serological marker for at least one TTD. Taking as an example the scenario of a $4 \%$ prevalence of tattoos among the hypothetical population, and a $10 \%$ prevalence of a positive test for at least one of the TTDs the $2 \times 2$ table thus obtained is shown in Table 3. From this table it can be calculated that if all subjects with tattoos were deferred from blood donation, 11\% (120 out of 1080) of the total number of individuals who would test positive for at least one TTD (and therefore only deferred after the serological tests were performed) would be excluded from donation without having to do the blood tests, at a cost of 280 tattooed individuals who would be unnecessarily deferred. At an estimated cost of US $\$ 50$ in Brazil for a battery of serological tests plus the transfusion bag, US $\$ 6,000$ per year would be saved in this hypothetical blood bank. If the figures are extrapolated to Brazil as a whole, for a rough estimate of 1,400,000 new donors per year, US\$ 840,000 would be saved at a cost of 39,200 individuals being unnecessarily removed from the pool of blood donors.

Our previous study on the number, type and design of tattoos and their association with TTDs was restricted, and showed, on crude analysis, that multiple tattoos and nonprofessional (as opposed to professional) tattoos were associated with positive serological tests for TTDs [55,57] (Table 1). Analysis of the whole dataset (therefore including the nontattooed individuals) for the outcome of having at least one positive serological test for a TTD showed crude odds ratios of 4.28 (95\% CI: $2.47,7.42), 5.95$ (95\% CI: $3.29,10.81)$, and 4.71 (95\% CI: $2.72,8.16)$ for, respectively, having two or more tattoos (as opposed to one or none), having a nonprofessional tattoo, and for having one or the other. Using these figures as relative risks and in the same scenario of $4 \%$ prevalence of tattoos among the hypothetical population of 10,000 blood donors and of $10 \%$ prevalence of a positive test for at least one of the TTDs in the reference group, we obtained the figures shown in Tables 4 and 5. It should be noted that in these tables a proportion of the individuals with tattoos became part of the reference group. Although direct comparisons between Table 3, 4 and 5 can be criticized because the prevalence of a positive test for a TTD is artificially equal, they nevertheless give an idea of the impact of the choice of different tattoo deferral criteria. From these tables, it can be seen that the sensitivity decreases when more strict deferral criteria are adopted, from 0.11 (Table 3) to 0.05 (Table 4) and 0.08 (Table 5). On the other hand the specificity increases slightly, from 0.97 (Table 3) to 0.99 (Tables 4 and 5). In other words, selection of categories of tattooed individuals with a higher relative risk of testing positive for a TTD than other tattooed subjects decreases the number of individuals that should eventually be deferred from blood donation. In the examples shown in Tables 4 and 5, deferral of those individuals belonging to the more at risk subgroups of tattooed individuals would result in a smaller loss of potential donors and some savings in terms of the costs of serological tests.

\section{Discussion}

The World Health Day 2000 had as its theme "Safe blood starts with me, safe blood saves lives", focusing on an issue that is a very important and timely public health problem. Transfusions are still widely used in medicine and surgery and they are likely to remain necessary for many years. Safe blood requires testing of donated blood for a growing number of TTDs by laboratory tests that have become more expensive as they have become more sophisticated. Providing safe 
Table 1. Crude and adjusted odds ratios for tattoos and transfusion-transmitted diseases (TTDs), assessed by positive serological tests in a Brazilian hospital and blood bank, April 1998-January 2000 (summarized from Nishioka [55])

\begin{tabular}{|c|c|c|}
\hline & \multicolumn{2}{|c|}{ Odds ratio $(95 \% \mathrm{CI})$} \\
\hline & Crude & Adjusted \\
\hline \multicolumn{3}{|l|}{ Presence* } \\
\hline Yes vs. No & $2.99(1.71,5.26)$ & $2.05(1.11-3.81)^{\#}$ \\
\hline \multicolumn{3}{|l|}{ Number** } \\
\hline 2 vs. 1 & $4.45(1.96,10.09)$ & $2.19(0.75,6.34)^{\# \#}$ \\
\hline$\geq 3$ vs. 1 & $5.69(2.58,12.39)$ & $2.98(1.03,8.64)^{\# \#}$ \\
\hline \multicolumn{3}{|l|}{ Type $^{* *}$} \\
\hline Nonprofessional vs. professional & $3.30(1.70,6.41)$ & $3.25(1.39,7.59)^{\&}$ \\
\hline
\end{tabular}

Table 2. Expected number of TTD seropositive donors with tattoos in different scenarios of combinations of proportion of tattoos among the donor population $(2 \%$ and $4 \%)$ and positive screening serological tests for TTDs among the individuals without tattoos $(5 \%, 10 \%$ and $15 \%)$ for 10,000 hypothetical new blood donors* assuming a relative risk of 3 for individuals with tattoos having a positive serological marker for at least one TTD

\begin{tabular}{cccc}
\hline $\begin{array}{c}\text { Proportion of } \\
\text { tattoos among } \\
\text { blood donors }\end{array}$ & $\begin{array}{c}\text { Proportion of } \\
\text { positive serological } \\
\text { tests among subjects } \\
\text { without tattoos }\end{array}$ & $\begin{array}{c}\mathbf{N}^{\text {o. }} \text { of tattooed } \\
\text { donors }\end{array}$ & $\begin{array}{c}\mathbf{N}^{\text {o. }} \text { of seropositive } \\
\text { tattooed donors }\end{array}$ \\
\hline $2 \%$ & $5 \%$ & 200 & 30 \\
$2 \%$ & $10 \%$ & 200 & 60 \\
$2 \%$ & $15 \%$ & 200 & 90 \\
$4 \%$ & $5 \%$ & 400 & 60 \\
$4 \%$ & $10 \%$ & 400 & 120 \\
$4 \%$ & $5 \%$ & 400 & 180 \\
\hline
\end{tabular}

*Number of new blood donors expected in one year for a medium-sized blood bank in Brazil. 
Table 3. Figures for tattooed and non-tattooed subjects with or without at least one positive serological test for a TTD in a hypothetical population of 10,000 blood donors with a proportion of tattoos among the donor population of $4 \%$ and a proportion of positive screening serological tests for TTDs among the individuals without tattoos of $10 \%$

\begin{tabular}{lccr}
\hline Tattoo & $\begin{array}{c}\text { At least one positive } \\
\text { serological test for a TTD }\end{array}$ & $\begin{array}{c}\text { Negative serological } \\
\text { tests for TTDs }\end{array}$ & Total \\
\hline One or more & 120 & 280 & 400 \\
None & 960 & 8,640 & 9,600 \\
Total & 1,080 & 8,920 & 10,000 \\
\hline
\end{tabular}

Table 4. Individuals with 2 or more tattoos compared to those with 1 tattoo or none, with or without at least one positive serological test for a TTD, in a hypothetical population of 10,000 blood donors with a proportion of tattoos among the donor population of $4 \%$ and a proportion of positive screening serological tests for TTDs among the individuals with one tattoo or none of $10 \%$ (figures obtained assuming a relative risk of 6.0 , and that $20 \%$ of the tattooed individuals have 2 or more tattoos*)

\begin{tabular}{lccr}
\hline Tattoo & $\begin{array}{c}\text { At least one positive } \\
\text { serological test for a TTD }\end{array}$ & $\begin{array}{c}\text { Negative serological } \\
\text { tests for TTDs }\end{array}$ & Total \\
\hline Two or more & 48 & 32 & 80 \\
One or none & 992 & 8,928 & 9,920 \\
Total & 997 & 9,003 & 10,000 \\
\hline
\end{tabular}

*Calculated from data from Nishioka [55].

Table 5. Individuals with nonprofessional tattoo(s) compared to those with professional tattoo(s) or none with or without at least one positive serological test for a TTD in a hypothetical population of 10,000 blood donors with a proportion of tattoos among the donor population of $4 \%$ and a proportion of positive screening serological tests for TTDs among the individuals with professional tattoos or without tattoos of $10 \%$ (figures obtained assuming a relative risk of 4.3 , and that $50 \%$ of the tattooed individuals have at least one nonprofessional tattoo*)

\begin{tabular}{lccr}
\hline Tattoo & $\begin{array}{c}\text { At least one positive } \\
\text { serological test for a TTD }\end{array}$ & $\begin{array}{c}\text { Negative serological } \\
\text { tests for TTDs }\end{array}$ & Total \\
\hline Nonprofessional & 86 & 114 & 200 \\
Professional/None & 980 & 8,820 & 9,800 \\
Total & 1,066 & 8,934 & 10,000 \\
\hline
\end{tabular}

*Calculated from data from Nishioka [55]. 
blood is an expensive task particularly for developing countries, where resources are scarce. In certain Latin American countries not all donors are screened even for the most prevalent or potentially serious infections. In Bolivia, for instance, only $36.2 \%$ of donors were screened for HIV infection in 1993 [59].

There is an obvious need for all donors to be tested for TTDs with sensitive and reliable serological tests, but efficient algorithms should be adopted so that losses of donated blood because of positive serological tests are kept to the minimum. Positive tests in asymptomatic blood donors lead to loss of valuable resources expended for the blood tests and the transfusion bag, and also create additional problems as these individuals have to have their diagnosis confirmed, which requires medical evaluation and more laboratory tests. In the United States approximately 4 percent of units are discarded because of a positive screening test (including alanine aminotransferase [ALT] testing) [60]. In Scotland approximately $1 \%$ of all donations are positive for at least one of the infections tested there [61].

We have already pointed out that use of repeat donors should be encouraged, and that efficient selection of blood donors might benefit from improving the screening interview, or by taking better advantage of the information already collected. In this study we showed that information on tattoos, which are already considered as a reason for temporary deferral depending on when they were performed, can be useful to improve the efficiency of the blood screening process. Although our previous study has shown that the association between tattoos and TTDs is of low magnitude when confounders are taken into account (OR: 2.05, 95\% CI: 1.11, 3.81) [55] (Table 1), tattoos have an advantage over other indicators of seropositivity for TTDs, which is the fact that their presence can be objectively determined by inspection. Information on almost all the other indicators relies on the subjective responses of the interviewee, which are not always reliable. It is not unlikely, for instance, that an individual who is an IV drug user, or who adopts high risk behavior for sexual transmitted diseases, denies this behavior on interview. There is abundant anecdotal evidence that this occurs for various reasons, that go from reluctance to provide the correct information to an interviewer of the opposite sex, to intention of having their blood tested (for HIV, for instance) free of charge. Tattoos, because of their association with some of these indicators, particularly IV drug use and previous incarceration, are, in fact, surrogates for these facts.

In the example discussed here, if extrapolation for a country like Brazil is valid (we are aware of the limitations of this assumption, but it gives an idea of the magnitude of the figures involved), a substantial amount of money would be saved by using only the presence of a tattoo as a deferral criterion. Obviously a large proportion of these individuals with tattoos would be deferred for other reasons that would come to light during the screening interview, but so eventually would be a proportion of non-tattooed individuals. The use of tattoos as a deferral criterion could be adopted or not depending on the trade-off between cost savings on blood tests plus follow-up of the individuals who test positive and losses in numbers of donors. In a scenario of a large pool of potential donors that could be reached by education or by campaigns, in other words, where losses of seronegative tattooed donors would not be a burden, tattoos could be a useful screening tool for the selection of blood donors. If the number of potential blood donors is a limiting factor, deferring blood donors with two or more tattoos, or with nonprofessional tattoos (which can also be determined by inspection in the majority of the cases) could be an option. The savings in terms of dollars would not be as substantial, but the losses from unnecessary deferral of blood donors would be minimized.

Our previous study on the association between tattoos and TTDs [55-57] was limited to a single teaching hospital and blood bank in Brazil, and inferences for the whole country should be done at best very cautiously. These data suggest that a larger multisite study on the association between tattoos (and tattoo types and numbers) and TTDs should be carried out to confirm our results. A larger study could also better assess whether other information regarding tattoos, such as the tattoo design, which was not shown to be important in our study $[55,57]$, can also be valid for the screening of blood donors. 


\section{Conclusion}

Limited evidence from a hospital-based study, that requires corroboration from larger population-based studies, suggests that tattoos could be an efficient (costsaving) criterion for the screening of blood donors in Brazil for settings with a large pool of potential donors. Restricting the deferral criterion to certain sub-groups of tattooed individuals could be an alternative for settings where the unnecessary deferral of seronegative donors is an issue.

\section{References}

1. Carson J.L., Poses R.M., Spence R.K., Bonavita G. Severity of anaemia and operative mortality and morbidity. Lancet 1988; 1:727-9.

2. Hebert P.C., Wells G., Blajchman M.A., et al. A multicenter, randomized, controlled clinical trial of transfusion requirements in critical care. Transfusion Requirements in Critical Care Investigators, Canadian Critical Care Trials Group. N Engl J Med 1999;340:409-17.

3. Anderson N.A. Blood donors and blood collection. In: Pamphilon, D.H., ed. Modern Transfusion Medicine. Boca Raton: CRC Press, 1995, pp. 1-9.

4. Provan D. Better blood transfusion. BMJ 1999; 318:1435-6.

5. Cella D., Bron D. The effect of epoetin alfa on quality of life in anemic cancer patients. Cancer Pract 1999; 7:177-82.

6. Kleinman S., Williams A.E. Donor selection procedures: is it possible to improve them? Transfus Med Rev 1998; $12: 288-302$.

7. Regan F.A.M., Hewitt P., Barbara J.A.J., Contreras M. Prospective investigation of transfusion transmitted infection in recipients of over 20000 units of blood. BMJ 2000;320:403-6.

8. Moraes-Souza H. Política nacional de sangue e hemoderivados. Condepol/Brasil 1999;4:118-20, 122-3.

9. Davis A.R. Tattoo parlours and hepatitis $C$ virus infection. Med J Aust 1995; 163:556-7.

10. Héma-Québec. Manuel des critères de sélection des donneurs. Manuel de Héma-Québec. Montréal, Québec, Canada, 2000.

11. Lim J.C., Tien S.L., Ong Y.W. Main causes of pre-donation deferral of prospective blood donors in the Singapore Blood Transfusion Service. Ann Acad Med Singapore 1993;22:326-31.
12. Beerman H., Lane R.A.G. Tattoo: a survey of the literature concerning the medical complications of tattooing. Am J Med Sci 1954;227:444-65.

13. Mowat N.A.G., Brunt P.W., Albert-Recht F., Walker W. Outbreak of serum hepatitis associated with tattooing. Lancet 1973; 1:33-4.

14. Limentani A.E., Elliott L.M., Noah N.D., Lamborn J.K. An outbreak of hepatitis B from tattooing. Lancet 1979; 2 :86-8.

15. Goh K.T. Hepatitis B surveillance in Singapore. Ann Acad Med Singapore 1980;9:136-41.

16. Doll D.C. Tattooing in prison and HIV infection. Lancet 1988; $1: 66-7$.

17. Abildgaard N., Peterslund N.A. Hepatitis C virus transmitted by tattooing needle. Lancet 1991;338:460.

18. Long G.E. , Rickman L.S. Infectious complications of tattoos. Clin Infect Dis 1994;18:610-9.

19. Simonian P.T., Gilbert M., Trumble T.E. Incidence of hepatitis $\mathrm{C}$ in patients requiring orthopaedic surgery. $\mathrm{J}$ Bone Joint Surg Br 1995;77-B:971-4.

20. Brind A.M., Watson J.P., James O.F., Bassendine M.F. Hepatitis $C$ virus infection in the elderly. QJM 1996;89:291-6.

21. Sun D.X., Zhang F.G., Geng Y.Q., Xi D.S. Hepatitis C transmission by cosmetic tattooing in women. Lancet 1996;347:541.

22. Thompson S.C., Hernberger F., Wale E., Crofts N. Hepatitis $\mathrm{C}$ transmission through tattooing: a case report. Aust N Z J Public Health 1996;20:317-8.

23. Leyden J.J., Smith J.G. Jr, Chalker D.K., et al. Serologic survey for markers of hepatitis B infection in dermatologists. J Am Acad Dermatol 1985; 12:676-680.

24. Reed B.E., Barrett A.P., Smith M.W. The relationship of tattooing to hepatitis B virus exposure. Aust N Z J Med 1985; $15: 769-70$.

25. Hyams K.C., al-Arabi M.A., al-Tagani A.A., et al. Epidemiology of hepatitis B in the Gezira region of Sudan. Am J Trop Med Hyg 1989;40:200-6.

26. Pavli P., Bayliss J.A., Dent O.F., Lunzer M.R. The prevalence of serological markers for hepatitis B virus infection in Australian Naval personnel. Med J Aust 1989; $151: 71-5$.

27. Martelli C.M.T., Andrade A.L.S.S., Cardoso D.D.P., et al. Soroprevalência e fatores de risco para a infecção pelo vírus da hepatite B pelos marcadores AgHBs e antiHBs em prisioneiros e primodoadores de sangue. Rev Saude Publica 1990;24:270-6.

28. Ko Y.C., Lan S.J., Chang P.Y. An increased risk of hepatitis $B$ virus infection from tattooing in Taiwan. Kao Hsiung I Hsueh Ko Hsueh Tsa Chih 1990;6:237-43.

29. Sebastian V.J., Ray S., Bhattacharya S., et al. Tattooing and hepatitis B infection. J Gastroenterol Hepatol 1992;7:385-7. 
30. Mele A., Corona R., Tosti M.E., et al. Beauty treatments and risk of parenterally transmitted hepatitis: results from the hepatitis surveillance system in Italy. Scand J Infect Dis 1995;27:441-4.

31. Kaldor J.M., Archer G.T., Buring M.L., et al. Risk factors for hepatitis $\mathrm{C}$ virus infection in blood donors: a casecontrol study. Med J Aust 1992;157:227-30.

32. Ko Y.C., Ho M.S., Chiang T.A., et al. Tattooing as a risk of hepatitis C virus infection. J Med Virol 1992;38:288-91.

33. Holsen D.S., Harthug S., Myrmel H. Prevalence of antibodies to hepatitis $\mathrm{C}$ virus and association with intravenous drug abuse and tattooing in a national prison in Norway. Eur J Clin Microbiol Infect Dis 1993;12:673-6.

34. MacLennan S., Moore M.C., Hewitt P.E., et al. A study of anti-hepatitis $\mathrm{C}$ positive blood donors: the first year of screening. Transfus Med 1994;4:125-33.

35. Neal K.R., Jones D.A., Killey D., James V. Risk factors for hepatitis $\mathrm{C}$ virus infection: a case-control study of blood donors in the Trent Region (UK). Epidemiol Infect 1994; 112:595-601.

36. Chang C.J., Ko Y.C., Liu H.W. Seroepidemiology of hepatitis $\mathrm{C}$ virus infection among drug abusers in southern Taiwan. J Formos Med Assoc 1998;97:826-9.

37. Balasekaran R., Bulterys M., Jamal M.M., et al. A casecontrol study of risk factors for sporadic hepatitis $\mathrm{C}$ virus infection in the southwestern United States. Am J Gastroenterol 1999;94:1341-46.

38. Brusaferro S., Barbone F., Andrian P., et al. A study on the role of the family and other risk factors in $\mathrm{HCV}$ transmission. Eur J Epidemiol 1999; 15:125-32.

39. Delage G., Infante-Rivard C., Chiavetta J.A., et al. Risk factors for acquisition of hepatitis $\mathrm{C}$ virus infection in blood donors: results of a case-control study. Gastroenterology 1999;116:893-9.

40. Paraná R., Vitvitski L., Andrade Z., et al.. Acute sporadic non-A, non-B hepatitis in northeastern Brazil: etiology and natural history. Hepatology 1999;30:289-93.

41. Estebanez-Estebanez P., Colomo-Gomez C., ZunzuneguiPastor M.V., et al.. Carceles y SIDA: factores de riesgo de infeccion por el VIH en las carceles de Madrid. Gac Sanit 1990;4:100-5.

42. Kuberski T., LeGonidec G., Gust I.D., et al. Hepatitis B virus infections in Melanesians and Polynesians in New Caledonia. Am J Epidemiol 1981;114:355-61.

43. Tibbs C.J. Hepatitis B, tropical ulcers, and immunisation strategy in Kiribati. BrMed J(Clin Res Ed) 1987;294:537-40.

44. Phoon W.O., Fong N.P., Lee J. History of blood transfusion, tattooing, acupuncture and risk of hepatitis B surface antigenaemia among Chinese men in Singapore. Am J Public Health 1988;78:958-60.

45. Siebke J.C., Wessel N., Kvandal P., Lie T. The prevalence of hepatitis A and B in Norwegian merchant seamen a serological study. Infection 1989;17:77-80.
46. Dufour A., Alary M., Poulin C., et al. Prevalence and risk behaviours for HIV infection among inmates of a provincial prison in Quebec City. AIDS 1996;10:1109-15.

47. Kim Y.S., Ahn Y.O., Kim D.W. A case-control study on the risk factors of hepatitis $\mathrm{C}$ virus infection among Koreans. J Korean Med Sci 1996; 11: 38-43.

48. Conry-Cantilena C., van Raden M., Gibble J., et al.. Routes of infection, viremia, and liver disease in blood donors found to have hepatitis C infection. N Engl J Med 1996;334:1691-6.

49. Garner J.J., Gaughwin M., Dodding J., Willson K. Prevalence of hepatitis $\mathrm{C}$ infection in pregnant women in South Australia. Med J Aust 1997; 166:470-2.

50. Sun C.A., Chen H.C., Lu C.F., et al. Transmission of hepatitis $\mathrm{C}$ virus in Taiwan: prevalence and risk factors based on a nationwide survey. J Med Virol 1999;59:290-6.

51. Murphy E.L., Bryzman S.M., Glynn S.A., et al. Risk factors for hepatitis $\mathrm{C}$ virus infection in United States blood donors. Hepatology 2000;31:756-62.

52. Watson J.M. Schoolchildren who tattoo themselves. Lancet 1984; 1:47

53. Rotily M., Delorme C., Obadia Y., et al. Survey of French prison found that injecting drug use and tattooing occurred. BMJ 1998;316:777.

54. Barezani E. Normas da triagem clínica do doador de sangue. Belo Horizonte: Fundação Centro de Hematologia e Hemoterapia de Minas Gerais, 1994, 24 pp.

55. Nishioka S.A. Tattoos as indicators of transfusiontransmitted diseases in Brazil: a matched hospital-based cross-sectional study [Doctoral thesis]. Montreal: McGill University, 2000, 166 pp.

56. Nishioka S.A., Gyorkos T.W., Joseph L., Collet J.-P. Selection of subjects for hospital-based epidemiologic studies based on outward manifestations of disease. Clin Invest Med 2001;24:299-303.

57. Nishioka S.A., Gyorkos T.W., Joseph L., et al. Tattooing and risk for transfusion-transmitted diseases: the role of the type, number and design of the tattoos, and the conditions in which they were performed. Epidemiol Infect 2002; 128:63-71.

58. Nishioka S.A., Oliveira S.A., Arantes S.C.F., Valente S.R.G. Ear-piercing and tattooing as indicators of positive serological tests for Chagas' disease in Brazilian male conscripts. Rev Soc Bras Med Trop 1997;30(SI):114-115.

59. Schmuñis G.A., Zicker F., Pinheiro F., Brandling-Bennett D. Risk for transfusion-transmitted diseases in Central and South America. Emerg Infect Dis 1998;4:5-11.

60. Ownby H.E., Korelitz J.J., Busch M.P., et al. Retrovirus Epidemiology Donor Study. Loss of volunteer blood donors because of unconfirmed enzyme immunoassay screening results. Transfusion 1997;37:199-205.

61. Dow B.C. Microbiology confirmatory tests for blood donors. Blood Rev 1999;13:91-104. 